\title{
Bases Curriculares
}

para as Artes

Visuais no Ensino

Fundamental

Maria Lúcia Batezat Duarte 
Este texto teórico é referenciado pela prática docente da autora, de seus alunos e ex-alunos, e de professores do Ensino Fundamental. Os demais pensadores que respaldam a proposta apresentada são fontes primárias, isto é, autores que formularam o seu pensamento refletindo sobre dados coletados em investigação com crianças e adolescentes. As perguntas às quais se busca responder são: O que é possível ensinar? Como ensinar Artes Visuais no Ensino Fundamental? De cunho didático-pedagógico, o texto é subdividido em quatro subitens: Níveis de compreensão e aprendizagem; Conteúdos de Ensino de Artes Visuais; Aspectos do desenvolvimento infantil; e Exemplos sobre o trabalho em sala de aula a partir da proposta apresentada.

\section{Introdução}

A origem deste texto remonta há alguns anos e deriva do trabade Uberlândia, em Minas Gerais. Naquele momento o intento era encontrar fundamentos, nos quais ancorar um trabalho, que deveria ser coletivo e sistematizado por meio de leituras e discussōes sobre as práticas docentes.

As questóes em pauta percorriam um longo espectro, iniciavam com a própria concepção de arte, evoluíam para as diferenças entre atividades e conteúdos de ensino, e interrogavam a adequação de conteúdos a cada faixa etária dos alunos do Ensino Fundamental atendidos pela equipe lotada na Secretaria Municipal de Ensino.

Nesta versão, a proposta é enfatizar aspectos ligados à adequação de conteúdos a cada faixa etária dos alunos. O motivo dessa publicação são as persistentes lacunas e as inúmeras dúvidas encontradas atualmente entre os novos professores em formação.

Seráo destacados os diferentes níveis de compreensão que Henri Wallon (1979) atrelava a sua teoria sobre o desenvolvimento humano, pois ele observava essa evolução a partir das primeiras açóes infantis que denotavam interesse pelosobjetos mundo. Trata-se de um movimento que tem início na primeira infância com a exploraçáo sensorial (cinestesia) dos objetos externos e paulatinamente torna-se uma capacidade de memorizar, relembrar, refletir, 
e formular pensamentos sobre a experiência de vida nas dimensóes privada e social. O pensamento de Wallon possibilita organizar o ensino de Artes Visuais em observância às possibilidades e limitaçóes das crianças e adolescentes em suas diferentes fases. Os dados que ele oferece permitem que se estabeleça uma relação entre os conteúdos a serem trabalhados nas salas de aula de artes e os estágios biológicos, afetivos e cognitivos dos alunos. ${ }^{1}$

Embora a primeira década do século XXI tenha sido marcada pelos Estudos Culturais e pela Cultura Visual, a discussão sobre essas tendências não é o foco deste texto, uma vez que algumas dessas questóes foram abordadas em outro artigo (Duarte, no prelo). Os conteúdos indicados para o ensino das Artes Visuais preservam um modo "essencialista" de pensamento que encontra no ensino do desenho, e na fatura manual (mesmo com o auxílio de softwares especializados), os primórdios para qualquer tipo de expressão que requeira a imagem visual.

Talvez importe ressaltar que, na concepção de ensino de Artes Visuais a ser apresentada, a imagem visual artística ainda aparece dissociada das demais imagens visuais divulgadas na mídia e na cultura contemporânea. Nesta proposta, as Artes Visuais aparecem fortemente e particularmente associadas à reflexão humana, mesmo nesses tempos de aceleração exigida pelas novas tecnologias. A concepção de Arte que subjaz neste artigo é aquela indicada por Alfredo Bossi há muitos anos: "A arte é uma produção; logo, supõe trabalho. Movimento que arranca o ser do não ser, a forma do amorfo, o ato da potência, o cosmos do caos." (Bosi, 1986, p.13) Trata-se de uma concepção que, como queria Luigi Pareyson (1984), carrega em si o poder de transformação social pelo seu caráter de explicitação ou, como pontua Remo Bodei (1995), pelo seu poder de dar sentido, de oferecer significação à existência humana. Nesta concepção, mais do que a criatividade ou a novidade que a arte possa propiciar, implica a função da arte em articular, em tornar acessível e expresso na forma

\footnotetext{
${ }^{1}$ A palavra "biológico" é utilizada aqui para indicar as diferentes condiçốes do corpo no processo de crescimento e maturaçăo da criança. O termo "afetivo" remete tanto à afecçáo, no sentido de ser afetado (sensibilizado) por uma percepçáo visual, tátil, etc., quanto no sentido de estar interessado, conectado com algo.

${ }^{2} \mathrm{Na}$ década de 80 do século anterior, as propostas norte-americanas para o ensino de Artes Visuais apresentavam duas tendências o "contextualismo", representado especialmente por Vincent Lanier, e o "essencialismo" defendido por Brent e Marjorie Wilson. Para a primeira tendência, as soluçôes gráficas e plásticas da fatura do objeto artístico deveriam ser "descobertas" pelo seu produtor, para a segunda tendência caberia ao professor ensinar aos alunos as soluçóes gráficas e plásticas já descobertas anteriormente por artistas no decurso histórico desta prática.
} 
artística, os significados humanos, isto é, um modo humano e universalizante de compreender a experiência de viver dando visibilidade e sentido as suas contradiçóes e ambivalências.

\title{
Bases Curriculares para o Ensino de Artes Visuais
}

\begin{abstract}
A proposta curricular para o ensino de Artes Visuais resultante 1 das reflexóes empreendidas pode ser apresentada resumidamente em tabelas. Cada tabela apresenta um grande aspecto dos conteúdos de ensino que aparecem subdivididos no eixo vertical. Todas as tabelas são organizadas em dois grandes eixos: um eixo vertical, que considera as subdivisóes dos conteúdos de ensino, e um eixo horizontal, que considera os aspectos do desenvolvimento infantil. As relaçôes entre esses dois eixos básicos pressupóem um terceiro fator, de caráter fundamentalmente pedagógico, que orienta sobre os níveis de aprofundamento possíveis às diferentes faixas etárias e sobre as possibilidades/objetivos atribuídos a cada conteúdo. Este último fator é indicado nas Tabelas por meio das letras W, Y, Z.

Antes de discorrer sobre cada um desses componentes e apresentar as Tabelas plenamente, espera-se que a primeira Tabela apresentada a seguir possa ajudar na visualização do intento. Nesta primeira visualização, apesar da explicação ser fornecida adiante, salienta-se a possibilidade de reconhecer de imediato que um mesmo conteúdo além de ser continuamente retomado e ampliado, deverá apresentar níveis de complexidade diferentes e compatíveis com a faixa etária do aluno. O primeiro nível de complexidade é representado pela letra W, à qual as letras $\mathrm{Y}$ e Z, de complexidade crescente, são acrescidas paulatinamente.
\end{abstract}


Tabela 1 - Conteúdo "Elementos da Linguagem Visual”

\begin{tabular}{|c|c|c|c|c|c|c|}
\hline \multirow{2}{*}{$\begin{array}{l}\text { Elementos da } \\
\text { Linguagem } \\
\text { Visual }\end{array}$} & \multicolumn{2}{|c|}{$\begin{array}{c}1^{\mathrm{a}} \text { série } \\
\text { (Pré-escola) }\end{array}$} & \multirow{2}{*}{$\begin{array}{c}2^{\mathrm{a}} \mathrm{e} 3^{\mathrm{a}} \\
\text { séries } \\
\text { esquema }\end{array}$} & \multirow{2}{*}{$\begin{array}{l}4^{\mathrm{a}} \text { e } 5^{\mathrm{a}} \\
\text { séries } \\
\text { figura }\end{array}$} & \multirow{2}{*}{$\begin{array}{l}6^{\mathrm{a}} \text { e } 7^{\mathrm{a}} \\
\text { séries } \\
\text { figura }\end{array}$} & \multirow{2}{*}{$\begin{array}{r}8^{\mathrm{a}} \text { e } 9^{\mathrm{a}} \\
\text { séries } \\
\text { figura }\end{array}$} \\
\hline & garatuja & $\begin{array}{c}\text { pré- } \\
\text { esquema }\end{array}$ & & & & \\
\hline Linha & $\mathbf{W}$ & W & WY & WYZ & WYZ & WYZ \\
\hline Plano & W & W & WY & WYZ & WYZ & WYZ \\
\hline Cor/forma & W & W & WY & WYZ & WYZ & WYZ \\
\hline Bidimensionalidade & W & w & WY & WYZ & WYZ & WYZ \\
\hline Tridimensionalidade & W & W & WY & WYZ & WYZ & WYZ \\
\hline Textura & W & W & WY & WY & WYZ & WYZ \\
\hline Volume & W & W & WY & WY & WY & WYZ \\
\hline Luz e sombra & & & $\mathbf{W}$ & W & WY & WYZ \\
\hline
\end{tabular}

\section{Os níveis de compreensão e aprendizagem (As letras nas Tabelas)}

A publicação mais importante de Henri Wallon, médico, psicólogo e educador francês da primeira metade do século XX, é o livro denominado nas ediçóes portuguesas "Do acto ao pensamento" (1979). Ali, Wallon apresenta sua teoria de cunho psicogenético demonstrando que a criança inicia a sua investigação e aprendizagem por meio de açóes alicerçadas em suas possibilidades perceptivas e motrizes. Ao longo da infância ele diferencia três fatores básicos propiciadores da constituição humana: a cinestesia, a percepção, e a representação. Em relação à aprendizagem do desenho e das artes visuais, é possível argumentar que a "cinestesia" indica o nível de controle muscular, o grau de domínio que a criança já adquiriu sobre o seu movimento físico para poder desenhar (corpo, braço, mão, dedos,... $)^{3}$. A "percepção" indica o quanto do objeto (conjunto, detalhes) a criança capta e utiliza ao desenhar. Isto é, a sua

\footnotetext{
${ }^{3} \mathrm{O}$ termo cinestesia, empregado por Wallon em relação à motricidade, é diferente de "sinestesia", que remete às relaçôes entre dois sentidos diferentes, como por exemplo, o olfato e a visão. É realmente o termo CINESTESIA, indicando o ato de "aprender pelos sentidos", que interessa fundamentalmente a esta proposta.
} 
possibilidade de atenção e de recepção sensorial dos objetos do mundo. Com o termo "representação", Wallon indica o momento em que a percepção dos objetos deixa de ser momentânea (em ato), e passa a constituir marcas, registros mentais. No âmbito das Artes Visuais o nível de representação indica a capacidade infantil para armazenar e utilizar representaçóes mentais visuais de determinados objetos para realizar uma Representação Gráfica ${ }^{4}$, isto é, o desenho.

Os pais mais atentos perceberão, sem dúvida, que seu filho inicia as suas experiências com desenho produzindo riscos no papel (ou na terra, na parede), momento em que ele começa a exercitar o controle de seus movimentos (cinestesia). Após esse período começam a surgir relaçóes entre o gesto de desenho e os objetos do mundo externo, ainda que de modo incipiente (cinestesia e percepção). Mais tarde, desenhos simplificados, esquemáticos, mas bastante identificáveis com os objetos do mundo, indicarão a representação mental e gráfica desses objetos (cinestesia, percepção, representação). Para Wallon (1979) esses três fatores são cumulativos, isto é, após as primeiras conquistas, os níveis de capacidade cinestésica, perceptiva e representativa estarão sempre interferindo, cada um a seu modo, no desenho infantil. Com Wallon compreende-se também que o desenvolvimento do desenho infantil ocorre por fases, acompanhando o próprio desenvolvimento integral da criança, isto é, o tempo e a experiência vivida propiciam graus diferentes de dificuldades vencidas, correspondentes à maturidade adquirida.

Por isso, além dos eixos horizontal (aspectos gráficos e plásticos do desenvolvimento infantil) e vertical (conteúdos de ensino), as tabelas que sintetizam esta proposta curricular do Ensino de Artes Visuais apresentam as letras WYZ dispostas nos pontos de encontro entre os eixos horizontais e verticais (conteúdo $\mathrm{X}$ idade/série). Essas letras, são sinais que visam relacionar o desenvolvimento infantil aos conteúdos propostos, indicando os possíveis níveis de compreensão e elaboração dos alunos nasaulas de arte. A partirdosfatores indicados por Wallon (cinestesia, percepção, representação), propóem-se três níveis de aprofundamento e complexidade na aprendizagem que são, ao mesmo tempo, ampliadores e relacionais. Isto é, passa-se a indicar ações físicas e mentais que podem caracterizar os níveis de compreensão e aprendizagem que pontuam as diferentes fases do desenvolvimento infantil. Desta maneira pretende-se que

${ }^{4}$ Ver para isso: Wallon (1979) e Duarte (1995). 
o professor de Artes Visuais entrelace a capacidade de compreensão e aprendizagem de seus alunos a sua maturidade psicológica e cognitiva.

\subsection{Primeiro Nível: W- Cinestésico explorador}

Pressupóe um primeiro contato do aluno com o conteúdo correspondente realizado a partir das possibilidades e da sensibilidade do próprio corpo. A experiência do conteúdo ocorre muito mais enquanto ato, ação, momento, do que enquanto consciência ou reflexão. É uma ação espontânea, intuitiva, particular, e por isso mesmo expressiva. Relaciona-se com as modalidades sensoriais: pegar, cheirar, ver, amassar, riscar, empilhar, provar, chacoalhar, etc.

\subsection{Segundo Nível: Y - Identificatório diferenciador}

Considera-se aqui a capacidade do aluno de identificar e, portanto, de diferenciar elementos e conceitos, ainda que apenas de modo bastante elementar. Não se busca ainda as posteriores reflexões e justificativas.Trata-se de um início de reflexão que já permite à criança a partir de determinadas identificaçóes (por exemplo: a linha mais fina é diferente da linha mais grossa) começar a explorar e a experimentar por sua própria deliberação, conscientemente, algumas variáveis formais e conceituais.

\subsection{Terceiro Nível: $Z$-Conceitual reflexivo}

Entende-se que neste momento do seu desenvolvimento a criança já é hábil a iniciar a elaboração de conceitos. Além de explorar cinestesicamente a sua capacidade de desenhar e relacionar-se com os objetos do mundo, de identificar diferentes soluçóes plástico-visuais dadas às figuras e formas, a criança é capaz de adquirir e construir sentidos verbais, justificativas, explicaçóes, para os objetos visuais que lhes são apresentados e para as diferentes informaçóes teóricas que lhe são fornecidas. Mantém, entretanto, na sua produção nas salas de aula de artes, a particularidade e a expressividade que a diferencia e confere ao objeto, por ela construído, uma identidade. 


\section{Conteúdos de Ensino de Artes Visuais: ( Eixo vertical nas Tabelas)}

No eixo vertical das Tabelas são apresentados os conteúdos de ensino, os conhecimentos fundamentais a serem adquiridos no âmbito das Artes Visuais.

As duas primeiras Tabelas de conteúdos, Elementos da Linguagem Visual e Elementos de Composição e Estrutura Espacial, são compostas por conceitos pertinentes à Teoria da Forma. Trata-se dos elementos que compóem a unidade da linguagem visual (que se denomina figura); e dos elementos referentes à construção e estrutura espacial da composição visual, aqueles que determinam o modo como as várias figuras que compóem o espaço relacionam-se entre si. Artista plástico e professor da famosa escola alemã Bauhaus, Wassily Kandinsky relatou o planejamento de suas aulas e comentou sua produção artística considerando fundamentalmente os conceitos apresentados nas tabelas 1 e 2 em três importantes livros: "Curso da Bauhaus" (1987), "Ponto, linha, Plano" (1987), e "Do espiritual na arte" (1990). Rudolf Arnheim, um dos mais importantes teóricos da arte do século XX, tratou profundamente desses elementos em "Arte e percepção visual". No Brasil, a professora e artista plástica Fayga Ostrower descreveu no livro "Universos da arte" aulas ministradas para adultos utilizando esses conteúdos de ensino. Importa esclarecer que a partir dos anos noventa os princípios da Teoria da Forma (Gestalt) vêm sendo revisitados e comprovados cientificamente por meio de investigaçóes no campo da neuroestética. ${ }^{5}$

Se é fundamental que todo o professor de arte domine esses conteúdos, uma vez que eles são os dados possíveis para uma análise formal da produção dos seus alunos em sala de aula de artes (e da produção dos artistas), é fundamental também que ele saiba utilizar este referencial no momento e na dosagem correta em suas aulas, atendendo principalmente à faixa etária, à capacidade e ao interesse do seu alunado.

${ }^{5}$ Ver para isso, por exemplo: Zeki (2002). 
Tabela 2 - Elementos de Composiçáo e Estrutura Espacial

\begin{tabular}{|c|c|c|c|c|c|}
\hline $\begin{array}{l}\text { Elementos de } \\
\text { Composição e } \\
\text { Estrutura Espacial }\end{array}$ & $\begin{array}{c}1^{\mathrm{a}} \text { série } \\
\text { (Pré-escola) }\end{array}$ & $\begin{array}{l}2^{\mathrm{a}} \text { e } 3^{\mathrm{a}} \\
\text { séries }\end{array}$ & $\begin{array}{l}4^{\mathrm{a}} \text { e } 5^{\mathrm{a}} \\
\text { séries }\end{array}$ & $\begin{array}{l}6^{\mathrm{a}} \text { e } 7^{\mathrm{a}} \\
\text { séries }\end{array}$ & $\begin{array}{l}8^{\mathrm{a}} \text { e } 9^{\mathrm{a}} \\
\text { séries }\end{array}$ \\
\hline a. Figura/ Fundo & $\mathbf{W}$ & WY & WY & WYZ & WYZ \\
\hline Simetria/Assimetria & & WY & WY & WYZ & WYZ \\
\hline Ritmo & $\mathbf{W}$ & $\mathbf{W}$ & $\mathbf{W}$ & WYZ & WYZ \\
\hline Equilíbrio & & $\mathbf{W}$ & $\mathbf{W}$ & WYZ & WYZ \\
\hline b. Espaço Topológico & $\mathbf{W}$ & $\mathbf{W}$ & WY & WYZ & WYZ \\
\hline Espaço Projetivo & & WY & WY & WYZ & WYZ \\
\hline Espaço Euclidiano & & & & WY & WYZ \\
\hline
\end{tabular}

$\mathrm{Na}$ Tabela 2, que contempla os Elementos de Composição e Estrutura Espacial, é aberto um item especial (b) a respeito dos aspectos de estruturação do espaço plástico. No terceiro subtítulo, no qual são apresentados os argumentos sobre o eixo horizontal da proposta curricular (eixo do desenvolvimento infantil), será esclarecido que nas fases iniciais a criança organiza topologicamente o espaço plástico (Espaço Topológico), isto é, os objetos desenhados como que flutuam no espaço. Depois, ela passa a organizar esse espaço projetivamente (Espaço Projetivo), construindo-o a partir de um ponto de vista único e distribuindo os objetos sobre um mesmo plano (linha de base) e, depois, sobre planos que se sucedem no horizonte. Finalmente é apta a sugerir uma perspectiva usando recursos geométricos de "pontos de fuga" (Espaço Euclidiano) ${ }^{6}$.

Estes conceitos aparecem retomados e enfatizados aqui no eixo dos conteúdos, primeiramente porque indicam organizaçóes espaciais básicas do desenho infantil. Em segundo, para atualizar o dado de que, independentemente da faixa etária, é possível e procedente que qualquer criança ou adolescente, uma vez já tendo ultrapassado as dificuldades cinestésicas e perceptivas iniciais, construa o seu desenho a partir de qualquer um dos três diferentes tipos de espaço indicados. Isto é, uma criança plenamente apta a realizar um

${ }^{6}$ Ver para isso: Piaget e Inhelder (1993) ou Duarte (1995). 
desenho a partir dos princípios de perspectiva (Espaço Euclidiano), poderá construir o seu desenho sob a ótica, por exemplo, do Espaço Topológico. Esta é, aliás, uma solução usada a infinito por inúmeros artistas, entre eles, Paul Klee. Considera-se fundamental que o professor mantenha, garanta ao seu aluno, essas possibilidades.

$\mathrm{Na}$ terceira tabela são apresentadas, no eixo vertical (dos conteúdos), as concepçóes teóricas consideradas básicas.

Tabela 3 - Concepçóes Teóricas

\begin{tabular}{|l|c|c|c|c|c|}
\hline $\begin{array}{l}\text { Conceituações } \\
\text { Teóricas }\end{array}$ & $\begin{array}{c}\mathbf{1}^{\mathrm{a}} \text { série } \\
\text { (Pré-escola) }\end{array}$ & $\begin{array}{c}\mathbf{2}^{\mathrm{a}} \mathbf{e} \mathbf{3}^{\mathrm{a}} \\
\text { séries }\end{array}$ & $\begin{array}{c}\mathbf{4}^{\mathrm{a}} \mathbf{e} \mathbf{5}^{\mathrm{a}} \\
\text { séries }\end{array}$ & $\begin{array}{c}\mathbf{6}^{\mathrm{a}} \mathbf{e} \mathbf{7}^{\mathrm{a}} \\
\text { séries }\end{array}$ & $\begin{array}{c}\mathbf{8}^{\mathrm{a}} \mathbf{e} \mathbf{9}^{\mathrm{a}} \\
\text { séries }\end{array}$ \\
\hline Arte Erudita & $\mathrm{W}$ & $\mathrm{W}$ & WY & WYZ & WYZ \\
\hline Arte Popular & $\mathrm{W}$ & $\mathrm{W}$ & WY & WYZ & WYZ \\
\hline Artesanato & $\mathrm{W}$ & $\mathrm{W}$ & WY & WYZ & WYZ \\
\hline $\begin{array}{l}\text { Manifestações } \\
\text { Culturais Locais }\end{array}$ & $\mathrm{W}$ & $\mathrm{W}$ & WY & WYZ & WYZ \\
\hline Cultura Visual & $\mathrm{W}$ & $\mathrm{W}$ & WY & WYZ & WYZ \\
\hline Estudos Culturais & & & & Y & WYZ \\
\hline
\end{tabular}

A confusão conceitual entre arte, artesanato, arte popular e demais manifestaçóes culturais permanece uma questão a ser discutida e trabalhada com os alunos. No caso brasileiro essas questóes remontam à Lei 5692/71, quando a regulamentação da então Educação Artística era dúbia e atrelava a arte à profissionalização e a um aspecto manufatureiro, fabril.

Trata- se de, frente às ainda presentes confusóes conceituais, fazer esclarecimentos a fim de que, em consonância com as alteraçóes propostas pela LDB 9394/96 atente-se para aspectos de: diferenciação entre a produção inventiva, nos seus vários domínios, e a produção repetitiva atribuindo a cada uma seu sentido e valor; diferenciação e valorização das produçóes culturais locais que mantém a história, a tradição e a identidade cultural dos vários segmentos da nossa sociedade; revisão continua do conceito de arte enquanto linguagem expressiva e singular dos indivíduos, e das concepçóes cristalizadas de apreciação estética, como, por exemplo, o "gostar" limitado às pinturas figurativas e acadêmicas ainda tão presente em 
nossa sociedade; e esclarecimentos sobre as características culturais (e colonialistas) das sociedades e naçóes em cujo berço tendências atuais como os "Estudos Culturais" e a "Cultura Visual" ganham visibilidade.

Tabela 4 - História da Arte

\begin{tabular}{|c|c|c|c|c|c|}
\hline História da Arte & $\begin{array}{c}1^{\mathrm{a}} \text { série } \\
\text { (Pré-escola) }\end{array}$ & $\begin{array}{l}2^{\mathrm{a}} \text { e } 3^{\mathrm{a}} \\
\text { séries }\end{array}$ & $\begin{array}{l}4^{\mathrm{a}} \text { e } 5^{\mathrm{a}} \\
\text { séries }\end{array}$ & $\begin{array}{l}6^{\mathrm{a}} \text { e } 7^{\mathrm{a}} \\
\text { séries }\end{array}$ & $\begin{array}{l}8^{\mathrm{a}} \text { e } 9^{\mathrm{a}} \\
\text { séries }\end{array}$ \\
\hline Artistas & $\mathbf{W}$ & WY & WY & WYZ & WYZ \\
\hline Movimentos & & W & WY & WYZ & WYZ \\
\hline
\end{tabular}

$\mathrm{Na}$ quarta tabela, o eixo vertical (dos conteúdos) contempla a História da Arte. Trata-se aqui, mais do que trabalhar cronologicamente a história da humanidade a partir da produção de arte, possibilitar aos alunos o conhecimento dos vários estilos e poéticas ${ }^{7}$ cujos princípios nortearam a produção de inúmeros artistas no decorrer do tempo e ainda podem ser utilizados na produção contemporânea, ou devem ser conhecidos e compreendidos no seu contexto.

Considera-se objetivo fundamental deste componente curricular apresentar aos alunos as várias possibilidades de solução gráfico-plástica dadas a um mesmo tema, figura ou espaço, por diferentes artistas visuais em diferentes épocas. Trata-se de auxiliá-los em suas próprias representaçóes, no seu modo de perceber e decodificar os objetos do mundo.

Ainda no que tange aos conteúdos de ensino e no âmbito desta proposta, importa reconhecer que, dependendo do enfoque dado, uma técnica, isto é, um modo específico de empregar materiais e produzir arte, pode e deve ser considerado um conteúdo de ensino. Por exemplo: molhar o barbante em guache e com ele marcar o papel é um simples recurso técnico a partir do qual o professor vai trabalhar com seus alunos um outro conteúdo, por exemplo, a importância da linha como elemento da linguagem visual. Por outro lado, a apresentação da Monotipia como técnica e recurso artístico expressivo, é, ela própria, o conteúdo necessário de uma aula de Artes Visuais, uma

${ }^{7}$ Pareyson, em sua obra já citada neste texto, denomina "poética”, o conjunto de normas e regras que caracterizam determinado estilo, período, ou produção individual do artista. É nesse sentido que o termo é empregado aqui. 
vez que envolve um modo diferenciado de raciocínio em sua execução: o negativo das figuras.

\section{Aspectos do desenvolvimento infantil: (Eixo horizontal nas Tabelas)}

Os teóricos que analisaram a produção de desenhos de crianças até a adolescência apresentaram fases de desenvolvimento relacionadas com aspectos perceptivos visuais, sensoriomotores, afetivos e sociais que resultam em características gráficas e plásticas que marcam essa produção. Assim, é possível indicar etapas no desenhar infantil que são diferentes de acordo com a maturidade, a faixa etária, e a experiência em desenhar que a criança vai adquirindo. Essas etapas variáveis de acordo com a faixa etária e a maturidade da criança são, entretanto, bastante similares quando verificadas em diferentes épocas e diferentes culturas. Isto é, após mais de um século de estudos sobre o desenhar na infância as características dessa produção, especialmente nas fases iniciais, mantêm muitas semelhanças.

Nos Estados Unidos, Lowenfeld e Brittain (1970) elaboram as diferenças entre fases do desenho infantil tendo como recurso de análise e proposição as características gráficas gerais dos desenhos. Eles relacionaram estas características gráficas às fases do desenvolvimento cronológico infantil, indicando uma faixa etária média na qual cada uma das características gráficas apontadas aparece.

$\mathrm{Na}$ França, Georges-Henri Luquet (1969) analisou o desenho infantil e o seu desenvolvimento considerando o nível de "realismo" que apresentam, e Bruno Duborgel (1974), identificou em sua pesquisa as estruturas espaciais evidenciadas na produção infantil de desenhos relacionando-as às faixas etárias de seus produtores.

Para elaborar esta proposta de ensino e alocar os conteúdos em cada série, a classificaçáo proposta por Lowenfeld e Brittain (1977) ofereceu a cronologia que parecia mais adequada. Mas, para além desta cronologia, foram considerados aspectos do desenvolvimento perceptivo, cognitivo e afetivo indicados por Henri Wallon e retrabalhados nos níveis de compreensão e aprendizagem já apresentados.

No que se refere aos aspectos basicamente cronológicos, compreende-se que as pesquisas de Lowenfweld e Brittain mantêm 
pertinência e atualidade. Grande parte das suas observaçóes e da classificação que propóem, coincidem, de modo bastante próximo, ao desdobramento em séries ou níveis de aprendizagem do nosso sistema nacional de ensino. É necessário recordar apenas que os autores, em consonância com a sua época, enfatizaram o valor dos processos de criação a serem experimentados pelas crianças nas salas de aula de Artes Visuais em detrimento ao produto obtido. Eles ressaltavam assim, uma concepção de ensino de Arte superada. É preciso separar a pertinência das suas observaçôes referentes às capacidades cognitivas, sociais e afetivas observadas para cada etapa escolar, das anotaçóes referentes aos objetivos pedagógicos, reorientando-os, como propóem Brent e Marjorie Wilson (1982), para os interesses evidenciados pela criança e não para a concepção artística adulta dos professores.

A criança em período pré-escolar (Educação Infantil) estaria vivenciando, segundo Lowenfeld e Brittain, primeiramente a fase das garatujas e, na seqüência, a fase pré-esquemática. Neste período de desenvolvimento, os domínios sensoriomotor e perceptivo infantil enfrentam níveis de grande dificuldade, mas de desenvolvimento bastante acelerado. A criança deve superar a dificuldade primeira de pegar (pinçar) o lápis, ou outro agente qualquer de desenho, e com ele imprimir uma marca sobre o papel, mas ela conhece a conquista, conseqüente, de apresentar por meio do desenho um objeto que lhe parece significativo. Nesta etapa, a estrutura espacial dos desenhos corresponde apenas às possibilidades e interesses da criança em apresentar graficamente objetos do mundo. Não há ainda condiçóes nem intenção em estabelecer relaçóes de proporcionalidade ou de pontos de vista perceptivos entre os objetos desenhados. Denomina-se esta estrutura espacial (ver Figura 1$)^{8}$, na qual os objetos como que flutuam na folha de papel sem que haja uma evidente conexão entre eles, "Espaço Topológico"”.

${ }^{8}$ Nas figuras a seguir, a representação menor, ao lado do desenho infantil, sintetiza o tipo de estrutura espacial.

${ }^{9}$ Ver para isso Piaget e Inhelder (1993). 

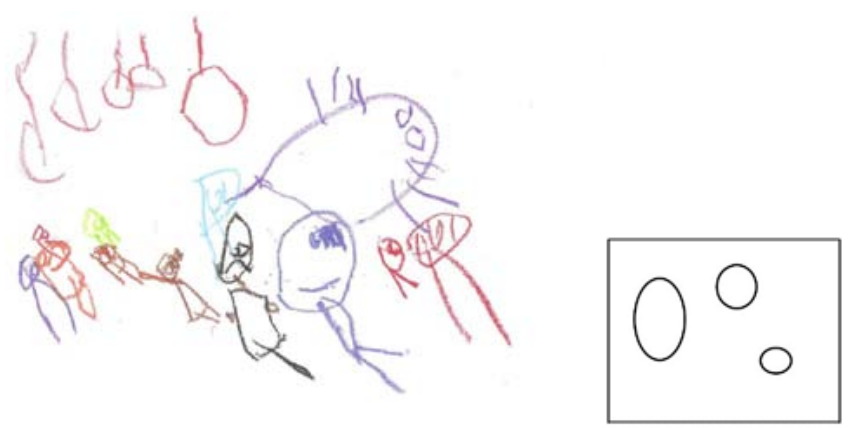

Fig. 1. Exemplo de "Espaço Topológico" - Davi 5a7m

Nas tabelas que resumem a proposta curricular, a indicação dos aspectos gráficos e plásticos do desenvolvimento infantil aparece relacionada à seriação escolar e não à faixa etária. Por quê? Porque se considera a faixa etária média ou padrão na qual a criança freqüenta estas séries, ou seja, entre 5 e 6 anos de idade freqüentam a primeira série, entre 7 a 9 anos de idade as segundas e terceiras séries do Ensino Fundamental, entre 9 a 11 anos de idade as quartas e quintas séries, entre 11 a 13 anos de idade as sextas e sétimas séries, e entre 13 a 15 anos de idade as oitavas e nonas séries do Ensino Fundamental. Entende-se que o professor em situação de ensino regular pode e deve pautar-se por essa referência, ainda que em sua sala de aula existam alguns alunos mais novos ou mais velhos. A situação modifica-se se a realidade docente é de, por exemplo, uma sala de aula de segunda série freqüentada em grande maioria por alunos de 14,15 anos de idade. Neste caso, compete ao professor considerar as variáveis e, com bom senso, usar como referência de planejamento o que está exposto para oitavas e nonas séries se isso lhe parecer mais conveniente.

No desenho de crianças de segunda e terceira séries do Ensino Fundamental, consolida-se a presença de esquemas de desenhos (a Fase Esquemática, segundo Lowenfeld e Brittain). O esquema do desenho é índice de conquista da representação mental do objeto desenhado ${ }^{10}$.

\footnotetext{
${ }^{10}$ Esta característica gráfica será relacionada ao fechamento do trinômio proposto por Wallon: cinestesia, percepção e representaçáo
} 
Surge, então, a preocupação infantil com a organização do espaço do desenho (conquista da visualidade ampla), e com esta preocupação as primeiras paisagens e cenários. O papai e a mamáe desenhados desde a primeira série (pré-escola), agora aparecem representados em um determinado lugar: no campo, na sala, ou na cozinha. O desenho infantil passa a apresentar um ponto de vista único e uma linha de base. Estabelece-se uma mudança fundamental na estrutura espacial dos mesmos com a conquista progressiva do "Espaço Projetivo" (Fig. 2 e 3).



Fig. 2. Espaço Projetivo - com 1 linha de base- Luan 8a8m

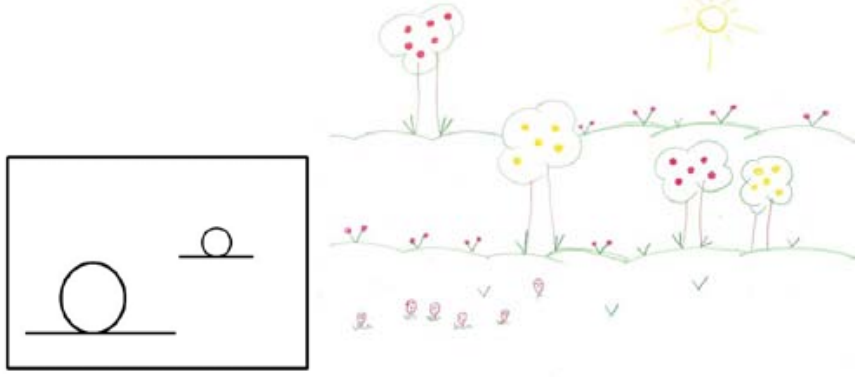

Fig. 3. Espaço Projetivo - com 2 linhas de baseLuísa 8a4m

Não raro, a criança de quarta série do Ensino Fundamental, de 9 anos de idade em diante, já representa graficamente os objetos do mundo atendendo às suas características básicas e recorrendo a uma série de detalhes que passam a caracterizá-los com maior precisão. Por exemplo: o acréscimo de um determinado tipo de cabelo e penteado que caracteriza certa pessoa. Lowenfeld e Brittain nomeiam estas etapas subsequentes do desenvolvimento do desenho como Alvorecer do 
Realismo (9 aos 12 anos) e Fase Pseudonaturalista (12 aos 14 anos). Trata-se, como também verificou Luquet (1969), da aproximaçáo sistemática e desejada à representação dos objetos e cenas do mundo tendo como referência um progressivo "realismo visual". 11

Deste momento em diante, nomeia-se o objeto desenhado (na Tabela síntese) não mais "esquema" (ou pré-esquema), mas figura. Considera-se "figura" todo (e cada) objeto apresentado no desenho. Um único desenho pode apresentar, por exemplo, quatro figuras: uma casa, uma árvore, um lago, uma pessoa.

A partir dessa faixa etária o estudante passa a buscar o "realismo visual" também no que se refere à estrutura espacial dos desenhos. O Espaço Projetivo vai adquirindo complexidades (multiplicidade de planos) e passa, geralmente, a "querer ser" Euclidiano. Mas, para isso, o aluno precisa da ajuda do professor. O Espaço Euclidiano pressupóe a representação bidimensional da tridimensionalidade, isto é, o artifício da perspectiva através de linhas e pontos de fuga (Fig. 4).

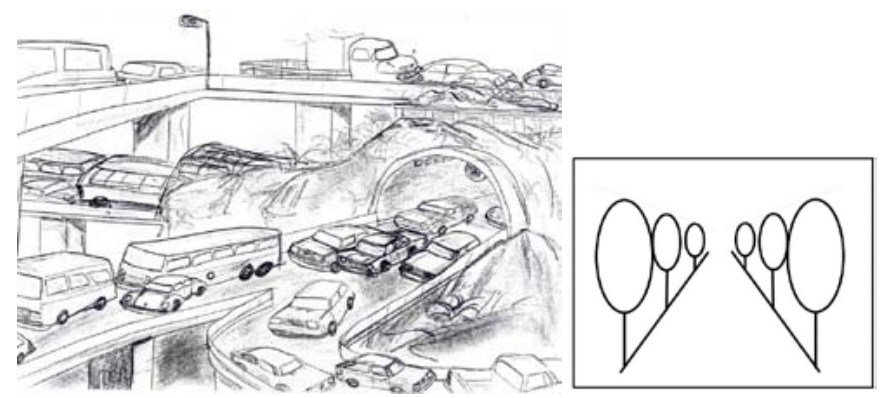

Fig. 4 - Espaço Euclidiano - Perspectiva - Marcelo 13a 4m

\section{Exemplos sobre o trabalho em sala de aula a partir da pro- posta apresentada}

Usando o conteúdo de ensino LINHA, nas diversas séries do Ensino Fundamental teríamos, entre outras, as possibilidades de:

\footnotetext{
${ }^{11}$ Ver para isso: Luquet (1969).
} 


\subsection{Primeira Série (Pré-escolar)}

Após os 2 anos de idade, recebendo o material necessário, a criança garatuja espontaneamente. Constrói linhas espontaneamente. Experimenta seu corpo, seu gesto. Busca cada vez maior controle sobre a linha que traça no papel (ou na areia, ou no piso do pátio, ou na parede da sala,...). Estamos no nível cinestésico explorador. Compete ao professor apenas propiciar descobertas, brincar com seus alunos, construindo junto, ludicamente, porexemplo:Umalinhabemgrande

e uma linha pequena ____. Não se trata de medir ou limitar o tamanho das linhas, ou ainda pretender soluçóes iguais para todos os alunos. Trata-se de explorar o gesto de cada um, ajudá-los com "brincadeiras" que possibilitem o exercício do controle do movimento da mão e do braço que traça a linha. Importa enfatizar que nesta fase inicial, é fundamental, também, que o pré-escolar tenha tempo e material para explorar sozinho, do seu jeito, as suas relaçóes com o desenhar.

\subsection{Segundas e Terceiras Séries}

Nesta faixa etária os alunos já apresentam alguns esquemas de desenho: a figura humana, a casa, a árvore. É possível trabalhar o conteúdo de ensino linha nos níveis cinestésico explorador e identificatório diferenciador. Por exemplo, dialogando sobre os desenhos dos alunos e, depois, observando a obra de um artista:

- Onde, neste desenho do coleguinha Daniel, a linha é mais grossa? E mais fina?

- Por que as vezes a linha fica mais grossa?

- Ah, porque a gente "aperta" o lápis!

- E se a gente usa o lápis de modo bem leve?

- A linha fica levezinha também, fininha!

- Vamos experimentar? Façam um desenho com linhas fininhas e linhas grossas.

- Agora olhem esse desenho do artista Georg Grosz "Ele riu de Hindenburg" (Berlim, 1920) ${ }^{12}$. Georg já era adulto quando fez este desenho, e morava em um país chamado Alemanha, que fica bem longe do Brasil, na Europa. No desenho de Georg, onde a linha é mais grossa e onde a linha e mais fina? Quem quer inventar uma

\footnotetext{
${ }^{12}$ Para ver e acessar as obras de arte citadas neste texto verifique no final as indicaçóes sobre os sites da WEB que
} as disponibilizam. 
história sobre o desenho de Georg? O que os homens que ele desenhou estão fazendo?

\subsection{Quartas e Quintas Séries}

A representação mais "adequada" da figura humana é um dos problemas que os alunos dessa faixa etária propóem-se a enfrentar. Ora, a linha gráfica é o elemento necessário de enclausuramento dessas figuras. Trata-se agora de iniciar o trabalho nos três níveis: Cinestésico explorador; Identificatório diferenciador; e Conceitual reflexivo. A linha surge então, conceitualmente, como um possível limite estabelecido no plano. Limite este que recorta o plano e instaura a presença da figura. Seria possível propor, por exemplo: exercícios com a linha como limite e enclausuramento do plano originando uma figura (um conceito teórico); a construçáo de um personagem masculino ou feminino, utilizando para isso uma linha contínua, ininterrupta (a produção visual proposta); e um estudo sobre o modo como Fernand Léger constrói as suas figuras, apresentando "Os mergulhadores policrômicos" de 1946, acrescido de informaçóes sobre a vida e a obra deste artista plástico (estabelecendo relaçôes com conteúdos de História da Arte).

Importa registrar ainda, que ao analisar os resultados da produção proposta, compete ao professor rever os conceitos trabalhados e evidenciar o caráter inventivo e particular das diferentes soluçóes dadas, pelos alunos, na construção dos seus personagens.

\subsection{Sextas e Sétimas Séries}

Mantidos os três níveis de compreensão Cinestésico explorador; Identificatório diferenciador; e Conceitual reflexivo; e sempre atendendo ao caráter inventivo e particular da produção do aluno, propóem-se agora que a linha (o elemento de conteúdo escolhido para esses exemplos) seja trabalhada enquanto hachuras e texturas visuais destacando a(s) figura(s) do plano de fundo. Por exemplo: exercícios com a linha utilizada em hachuras e texturas visuais, destacando figuras do fundo (conceito teórico); a produção de desenho a partir da grafia de duas figuras na folha de papel marcando inicialmente apenas o seu contorno para posterior preenchimento com a caneta esferográfica em justaposição 
de linhas horizontais e/ou verticais, de modo que seu "interior" seja mantido após a exclusão (apagamento) das linhas feitas com o lápis preto (a produção visual proposta). Estes exercícios seriam entâo relacionados com a linha na obra de Vincent Van Gogh ("A noite estrelada", 1889), a linha na obra de Edvard Munch ("O grito", 1895, litografia), e/ou a linha na obra de artistas populares do Cordel Nordestino (estabelecendo relaçóes com conteúdos de História da Arte). Neste caso, e a partir desses exemplos de História da Arte seria possível trabalhar também os conceitos de arte e arte popular, ou as diferenças entre os estilos e as poéticas utilizados por Van Gogh e Munch ao realizar suas obras.

\subsection{Oitavas e Nonas Séries:}

Considerando agora os alunos plenamente aptos nos três níveis de compreensão, a linha passa a ser identificada e conceituada como elemento possível de estruturação de uma composição visual. Seria possível propor, por exemplo: exercícios em que a linha exerça a função de orientação e estruturação da composição plástico-visual como linha de base, como linha de horizonte ou como provocadora da ilusão de ótica de tridimensionalidade no plano bidimensional (conceitos teóricos); o desenho de uma paisagem na qual apareça uma linha de base e uma linha de horizonte ou a produção de uma composição plástico-visual por meio de linhas diagonais e de um ponto de fuga (as produçóes visuais propostas); e leituras formais de produçóes plásticas de um desenho infantil verificando as soluçóes dadas por uma criança de 8 anos ao utilizar a linha de base e a linha de horizonte, ou de produções de Michelangelo (“A sagrada família”, 1504) e/ou Salvador Dali ("A persistência da memória”, 1931), verificando o uso da linha de horizonte, ou ainda observando os efeitos óticos de tridimensionalidade dados pela linha na obra de Vasarely ("VegaNor", 1969) e os efeitos óticos de movimento dados pela linha na obra de Adriana Varejão de 2005, "Swimming Pool" (Piscina).

Importa recordar que os exemplos acima construídos têm a finalidade de esclarecer o pensamento didático-pedagógico que sustenta essa proposta curricular. A idéia não é oferecer um modelo a ser seguido, mas tornar o dito teórico mais pragmático e perceptível. 


\section{Considerações Finais}

$\mathrm{D}$

o ponto de vista biológico e neurológico já somos capazes, cientificamente, de detectar as áreas dos nossos cérebros onde são processados, por exemplo, as imagens das letras que formam as palavras, os sons das letras e palavras, a capacidade de identificar e nomear objetos, os significados que atribuímos às palavras, etc. Entretanto, o modo particular e único como cada uma dessas áreas cerebrais se relaciona permitindo que cada um de nós, usando a mesma língua materna, o mesmo limite de vocabulário, seja capaz de produzir uma fala ou uma escrita altamente personalizada ainda é um mistério.

Neste sentido o trabalho de ensinar à criança e ao adolescente a nossa língua portuguesa ou artes visuais é muito semelhante. Tem-se à disposição uma longa história da humanidade na qual esses campos da vida social e cultural dos agrupamentos humanos foram se sistematizando, organizando, ganhando regras e repetiçóes, momentos em que os possíveis erros de alguns foram se tornando as novas regras para outros: novos modos de falar, de escrever ou de fazer artes visuais. Sabe-se, enfim, como os outros antes de nós falavam, escreviam e faziam artes, mas, não se sabe como será o futuro. A tarefa de ensinar é realizada no tempo presente, um tempo de repetir e um tempo de transformar, um tempo entre o passado e o futuro. $\mathrm{O}$ professor náo pode prever o futuro e por isso não pode suspender o presente no tempo passado. $\mathrm{O}$ passado é unicamente a referência possível sobre os passos que a humanidade já percorreu: é uma experiência acumulada. Por isso, ao professor compete apenas oferecer as ferramentas, aquelas já testadas no passado, e acompanhar com bom senso as novas falas, as novas escritas e as novas produçóes artísticas que deverão surgir.

Não é possível prever o futuro do adulto que hoje é criança ou adolescente nas salas de aulas de artes visuais. Ele será um artista visual? Ou será um poeta? Na imprecisão do futuro, compete ao professor oferecer o conhecimento que dispóe, oferecer as "ferramentas" que poderáo dar suporte e método à reflexão do futuro artista ou do futuro poeta.

A tarefa empreendida neste texto foi tentar organizar, sistematizar e exemplificar uma maneira de trabalhar em sala de aula 
com as "ferramentas" disponíveis para o ensino de Artes Visuais. A intenção foi relacionar as diferentes etapas da vida infantil e adolescente com uma crescente complexidade e aprofundamento dos conteúdos de ensino. Espera-se que este texto tenha sido lido como um ponto de vista, como um modo, entre outros, de pensar o ensino de Artes Visuais.

Considera-se necessário, ainda, acrescentar alguns esclarecimentos referentes especialmente ao terceiro subtítulo deste texto "Aspectos do desenvolvimento infantil (Eixo horizontal nas Tabelas)":

a. O caráter realista atribuído ao desenho da criança e do adolescente na apresentação das características do desenvolvimento gráfico, corresponde frente às pesquisas dos autores consultados e citados, à mobilidade e ao interesse primeiro das faixas etárias em foco. Luquet (1969, p. 124) é taxativo: "O desenho infantil é do começo ao fim inteiramente realista." É importante não confundir o conceito de realismo em Luquet (definido como tendo a vida como temática), com o conceito de Realismo enquanto estilo artístico. O mesmo autor qualifica o desenho infantil muito mais como uma "forma de vida" do que como uma "forma de beleza". Isto é, compreende o interesse infantil pelo desenho centrado muito mais na configuração dos objetos e nas cenas do cotidiano, da vida, do que no exercício plástico de produzir resultados estéticos. ${ }^{13}$ Isto não significa, entretanto, a impossibilidade de propor aos alunos que se expressem gráfica e plasticamente no desenho utilizando formas e figuras sem qualquer correspondência ao mundo dos objetos visíveis, reais. Considera-se inclusive, importante, que paulatinamente seja trabalhado o gosto estético pela forma e pela cor independentemente de sua transcriçáo em objetos do mundo cotidiano. É necessário que a produçáo na sala de aula de arte náo fique limitada à representação objetiva do mundo, mas também, como propóem a arte moderna e contemporânea, possa adquirir o caráter poético da plasticidade e visualidade "desmaterializada".

b. O exposto neste texto não pode substituir, de modo algum, nem o pensamento reflexivo do professor, alicerçado na sua experiência cotidiana, nem a leitura dos autores citados. Acredita-se que pensar educação, em qualquer nível, exige pesquisa não apenas textual, mas pesquisa de campo na qual o aluno seja o foco da observação e tenha

${ }^{13}$ Ver para isso também, Duarte (2011). 
direito à palavra. Os autores utilizados aqui tiveram esse cuidado e disseram com o próprio texto, sem intermediários, os resultados obtidos em suas enquetes. Portanto, a leitura dos teóricos citados poderá propiciar um encontro mais aprofundado e profícuo. Além disso, as aceleradas mudanças tecnológicas e sociais vivenciadas nos últimos anos demandam cautela e a necessária atenção para o fato de que as geraçôes atuais têm nos meios eletrônicos um lugar de aquisição de imagens, de maturidade e de conhecimento visual inimagináveis quando a maioria das pesquisas e textos sobre a infância e adolescência foi publicada.

Finalmente, talvez seja interessante pontuar que os conteúdos aqui sugeridos não são úteis apenas para a formação do artista ou do apreciador de Artes Visuais. Ao contrário, esses conteúdos fazem parte de todo e qualquer processo humano que remeta à percepção e à produção visual, seja essa visualidade empregada nas artes, na arquitetura, na publicidade, na comunicação, na produção cinematográfica ou jornalística.

\section{Referências}

ARNHEIM, Rudolf. Arte e percepção visual. (nova versão) São Paulo: Pioneira EDUSP,1980.

ARNHEIM, Rudolf. Intuição e intelecto na arte. São Paulo: Martins Fontes, 1989.

BARBOSA, Ana Mae. A imagem no ensino da arte. São Paulo: Perspectiva, 1991. (Col Estudos).

BODEI, Remo. Le forme del bello, Bologna, IT: Il Mulino, 1995.

BOSI, Alfredo. Reflexóes sobre a arte. São Paulo: Àtica, 1986.

DUARTE, Maria Lúcia Batezat. Cultura visual, neurociência e diferentes discursos: entretenimento, publicidade, jornalismo e arte. No prelo para os Anais da ANPAP 2012.

DUARTE, Maria Lúcia Batezat. Desenho infantil e seu ensino a crianças cegas. Razóes e método. Curitiba: Insight, 2011.

DUARTE, Maria Lúcia Batezat. $O$ desenho do pré-adolescente: carac- 
teristicas e tipificação. Dos aspectos gráficos à significação nos desenhos de narrativa. Tese de Doutoramento, 1995, ECA/USP.

DUBORGEL, Bruno. Le dessin d'enfant. Paris: Jean-Pierre Delarge Editeur, 1976.

DUBORGEL, Bruno. Imaginaire et pedagogie. De l'iconoclasme scolaire a la culture des songes. Tese de doutoramento, defendida em 1981, em xerox, s/d.

KANDINSKY, Wassily. Do espiritual na arte. São Paulo: Martins Fontes, 1990.

KANDINSKY, Wassily. Curso da Bauhaus. São Paulo: Martins Fontes, 1987.

KANDINSKY, Wassily. Ponto, linha, plano. São Paulo: Martins Fontes, 1987.

LA TAILlE, Yves de; OLIVEIRA, Marta Kohl de; DANTAS, Heloysa. Piaget, Vygotsky, Wallon: teorias psicogenéticas em discussão. São Paulo: Summus, 1992.

LOWNFELD, Viktor; BRITTAIN,W. Lambert. Desenvolvimento da capacidade criadora. São Paulo: Mestre Jou, 1977.

LUQUET, Georges-Henri. O desenho infantil. Porto: Ed. do Minho, 1969. PAREYSON, Luigi. Os problemas da estética. São Paulo: Martins Fontes. 1984.

PIAGET, Jean; INHELDER, Barbel. A representação do espaço na criança. Porto Alegre: Artes Médicas, 1993.

OSTROWER, Fayga. Universos da arte. Rio de Janeiro: Campus, 1983.

VYGOTSKY, Lev. S. La imaginacion y el arte en la infancia. Madrid: Akal Editor, 1982.

VYGOTSKY, Lev. S. A formação social da mente. São Paulo: Martins Fontes, 1989. 3 ed.

VYGOTSKY, Lev. S. Pensamento e linguagem. Sáo Paulo: Martins Fontes, 1991. 3 ed.

WALLON, Henri; LURÇART, L. El dibujo del personaje por el niño. em xerox s/d. 
WALLON, Henri. Do acto ao pensamento. Ensaio de psicologia comparada. Lisboa: Moraes Editores, 1979.

WILSON, Brent. The superheroes of J.C. Holz. Plus an outline of a theory of child art. Art Education, nov., 1974. p. 2-8

WILSON, Brent. The artístic tower of Babel: inextricable links between culture and graphic development. Visual Arts Research, 1985. p. $90-104$

WILSON, Brent; WILSON, Marjorie. Uma visão iconoclasta das fontes de imagens nos desenhos de crianças, $A R T E$, n.1 e 2, São Paulo. 1982.

WILSON, Marjorie. I draw - you draw: the graphic dialogue. School Arts, out., 1981, p. 50-55.

WILSON, Brent; WILSON, Marjorie. Pictorial composition an narrative structure: themes and the creation of meaning in the drawings of egyptian and japanese children. Visual Arts Research, 1987, p. 10-21.

ZEKI, Semir. Neural concept formation and art: Dante, Michelangelo, Wagner. Journal of Consciousness Studies, n. 9, 2002, p. 53-76.

ZEKI, Semir. Artistic creativity and the brain. Science, v. 293, 2001, p. $51-52$.

\section{Referências para as obras de arte}

Para Georg Grosz: http://www.moma.org

Para Fernando Léger: http://www.musees-nationaux-alpesmaritimes.fr/fleger/

Para Van Gogh: http://www.vangoghgallery.com

Para Edvard Munch: http://www.edvardmunch.org/edvard-munch-paintings

Para Cordel Nordestino - J. Borges: http://artepopularbrasil.blogspot.com.br 
Para Michelangelo: http://eventos.sartrecoc.com.br

Para Salvador Dali: http://estoriasdahistoria12.blogspot.com.br

Para Victor Vasarely: http://www.op-art.co.uk/victor-vasarely

Para Adriana Varejāo: http://www.itaucultural.org.br/aplicexternas/ enciclopedia_ic 